\title{
Back to the Future - Has Medical Treatment of Glaucoma Improved?
}

\author{
Proceedings of a Symposium Presented at the \\ European Society of Ophthalmology 2015 Congress in Vienna, Austria on 8 June 2015
}

Chairman and Expert Reviewer: Carlo E Traverso

Symposium Speakers: Norbert Pfeiffer, ${ }^{1}$ Gábor Holló² and Lutz E Pillunat ${ }^{3}$

1. Department of Ophthalmology, Mainz University, Germany;

2. Glaucoma Service and Perimetry Unit, Department of Ophthalmology, Semmelweis University, Budapest, Hungary; 3. University - Eye Hospital Dresden, Germany

\begin{abstract}
These proceedings are based on a symposium that were presented at the European Society of Ophthalmology 2015 Congress in Vienna, Austria on 8 June 2015. The symposium was arranged to bring together leaders in ophthalmology to explore advances in the medical treatment of glaucoma. Many patients with glaucoma require combination therapy. Fixed-dose combinations represent a significant improvement in the medical treatment of glaucoma, being advantageous in terms of their association with good compliance and elimination of the wash-out effect. While preservatives are a historic necessity, their use is associated with increased ocular surface disease and higher indirect cost. The novel preservative-free tafluprost/timolol fixed-dose combination provides mean diurnal intraocular pressure (IOP) lowering of up to $40 \%$ from baseline and demonstrates similar efficacy with other prostaglandin/timolol fixed-dose combinations, is superior to its individual components and non-inferior to its individual components given concomitantly. The tafluprost/timolol fixed-dose combination is well-tolerated with low prevalence of hyperaemia. It is generally accepted that function loss follows structural damage and that normal-pressure glaucoma (NPG) and high-pressure glaucoma (HPG) represent that same disease, separated by an arbitrary pressure level. However, functional damage (pattern electroretinogram) is detectable prior to structural damage and NPG patients show less retinal nerve fibre layer and visual field loss compared with the same optic nerve head morphology HPG patients. NPG patients seem to lose connective tissue first whereas, in HPG, patients seem to lose retinal nerve fibres first. Thus, whether NPG and HPG are the same disease is an open question.
\end{abstract}

\section{Keywords}

Fixed-dose combinations, glaucoma, preservative free, tafluprost/timolol, high-pressure glaucoma (HPG), normal-pressure glaucoma (NPG)

Disclosure: Carlo E Traverso has received grants from Alcon, Allergan, Santen and Théa. Norbert Pfeiffer has received research grants from Santen, Alcon, Novartis and Allergan and speakers' honoraria from Santen, Alcon and Allergan. Gábor Holló is a Consultant for Alcon and Santen. Lutz E Pillunat has received lecture fees from Allergan and Santen and is on the Advisory Board for Allergan and Santen, and received grant support from Novartis.

Acknowledgements: Editorial assistance was provided by Catherine Amey at Touch Medical Media and funded by Santen.

Open Access: This article is published under the Creative Commons Attribution Noncommercial License, which permits any non-commercial use, distribution, adaptation and reproduction provided the original author(s) and source are given appropriate credit.

Received: 10 September 2015 Published Online: 21 December 2015 Citation: European Ophthalmic Review, 2015;9(2):132-7

Correspondence: Carlo E Traverso, Clinica Oculistica, V. le Benedetto XV, 5 - 16132, Genova, Italy. E: mc8620@mclinik.it.

Support: These symposia proceedings and the symposium itself have been produced and paid for by Santen. The views and opinions expressed are those of the authors and not necessarily those of Santen. This article reports the proceedings of a sponsored satellite symposium held at the European Society of Ophthalmology 2015 Congress and as such has not been subject to the journals usual peer-review process. The report was reviewed for scientific accuracy by the symposium chairman before publication.

New medical formulations for the treatment of glaucoma are likely to improve outcomes for patients. A novel preservative-free tafluprost/timolol fixed-dose combination has been shown, in clinical trials, to effectively lower intraocular pressure (IOP) and appears to be well tolerated. A satellite symposium was held at the European Society of Ophthalmology (SOE) congress in Vienna, Austria on the 8 June 2015 to look to the future and ask: has medical treatment of glaucoma improved? 


\title{
The Role of Preservative-free Medications and Fixed-dose Combinations in the Treatment of Glaucoma
}

\author{
Norbert Pfeiffer \\ Mainz University, Germany
}

In treating glaucoma, the dual aim is to preserve vision and lower IOP; however, the mission statement of the European Glaucoma Society (EGS)' guidelines states an additional concern: "The goal of treatment is to maintain patients' visual function and related quality of life... ." Thus, for the patient, quality of life in addition to IOP control is crucial. The EGS has published a scheme to show that target IOP depends on a series of factors that must all be treated as a whole (see Figure 1A). Included are glaucoma damage, life expectancy, additional risk factors (e.g. pseudo-exfoliation), untreated IOP and rate of progression.

Prostaglandin mono preparations reduce IOP effectively in patents with open-angle glaucoma (OAG) or ocular hypertension, bringing mean IOP down, e.g. from around $26 \mathrm{mmHg}$ at baseline to approximately $17 \mathrm{mmHg}$ at week $12 .{ }^{2}$ However, a significant number of glaucoma patients need more than one medication. In the Ocular Hypertension Treatment Study, $40 \%$ of patients were being treated with two or more medications after 5 years. ${ }^{3}$ Yet adding two or more medications can reduce compliance significantly. ${ }^{4}$ Besides a decrease in the percentage of patients who are compliant, other potential problems can develop with patients on multiple medications. Although patients are asked to wait a minimum of 5 minutes between dosing different medications to eliminate the potential to washout the first medication, not all patients will actually do this, reducing the potential treatment benefit. If a patient waits only 30 seconds, for example, only around half of the first drug is adsorbed. ${ }^{5}$ This underscores the role of fixed-dose combinations. Therefore, when administering adjunctive therapy, one additional agent, from a different class, can be added to initial monotherapy. ${ }^{1}$ It is advantageous to facilitate compliance by both minimising the number of drops and dosing frequency and using fixed-dose combinations if possible. When adjusting target IOP, the EGS has devised a useful flow chart that includes consideration of side effects, compliance, quality of life and the ocular surface (see Figure 1B).

Ocular surface disease is an umbrella term that includes dry eye disease (as assessed by Schirmer's test, break-up time, etc.), red eye, ocular discomfort, as characterised by itching, burning and foreign body sensation as well as allergy. Ocular surface disease is more frequent in patients with glaucoma. ${ }^{6}$ Quality of life declines with the increasing severity of dry eye disease ${ }^{7}$ and compliance presumably decreases as patients notice problems associated with their eye drops. In a crosssectional study, using the Ocular Surface Disease Index for measuring symptoms of dry eye, $59 \%$ of 101 patients reported symptoms in at least one eye; Schirmer's testing showed $61 \%$ of glaucoma patients with a decrease in tear production in at least one eye and corneal and conjunctival lissamine green staining showed positive results in $22 \%$ of patients whereas tear break-up time was decreased in $78 \%{ }^{8}$ Furthermore, benzalkonium chloride (BAK)-containing drops were associated with higher odds of showing abnormal results on the

\section{Figure 1: European Glaucoma Society ${ }^{1}-$ Determining Target IOP (A) and Adjusting Target IOP (B)}

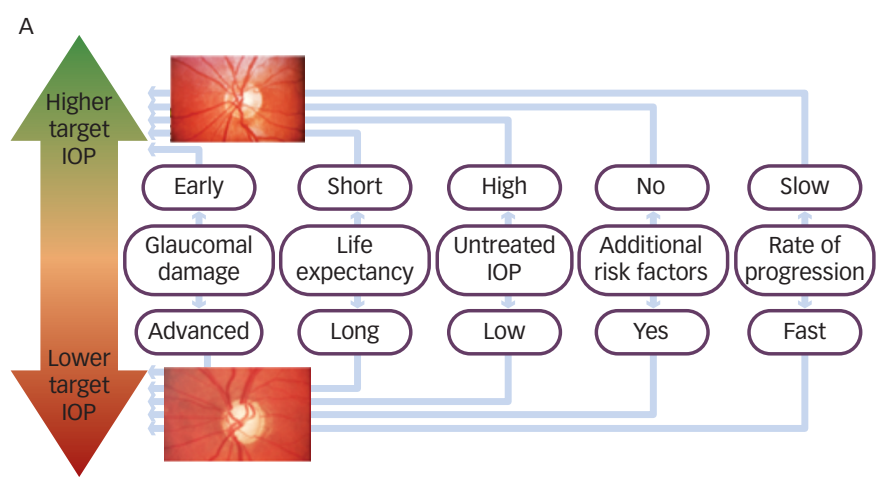

B

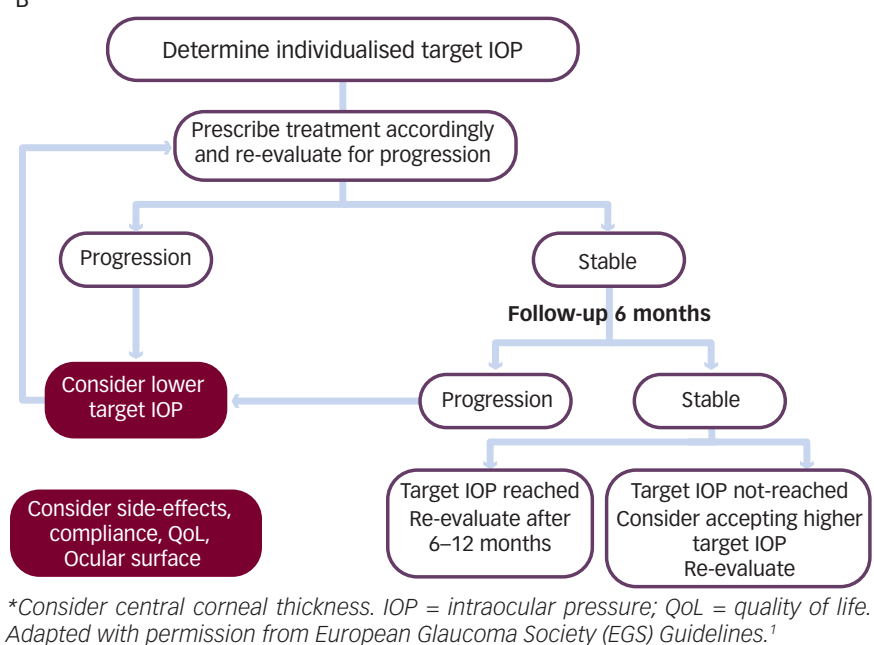

lissamine green staining test (odds ratio $=2.03 ; 95 \%$ confidence interval [Cl] 1.06-3.89; $p=0.034)$. In The German Glaucoma and Dry Eye Register (20,506 patients; 900 centres), ${ }^{6}$ more women were found to develop dry eye and glaucoma than men (56.9\% versus $45.7 \%$, respectively). Dry eye occurred with dissimilar frequencies in association with the various glaucoma types: pseudo-exfoliation > primary OAG > pigmentary glaucoma. Dry eye occurred more frequently when three or more anti-glaucoma drugs were used and increased with the duration of glaucoma and the use of preservatives. ${ }^{6}$

\section{Summary}

- A large number of glaucoma patients need combination therapy.

- Fixed-dose combinations are advantageous owing to improved compliance and elimination of the wash-out effect.

- Preservatives in glaucoma medications increase the prevalence of ocular surface disease. 


\title{
Novel Preservative-free Fixed-dose Combination of Tafluprost and Timolol
}

\author{
Gábor Holló
}

Glaucoma Service and Perimetry Unit, Department of Ophthalmology, Semmelweis University, Budapest, Hungary

Preservative-free fixed-dose combination of $0.0015 \%$ tafluprost and $0.5 \%$ timolol maleate has received regulatory approval in Europe. ${ }^{9}$ At the time of the symposium it was available in Germany, the Nordic countries and the UK and there were plans for its introduction in other EU countries in 2015.

\section{Superiority Study of Fixed-dose Combination versus its Components}

A stratified, double-masked, randomised, multicentre phase III study was conducted to compare efficacy, safety and tolerability of the preservative-free fixed-dose combination of tafluprost $0.0015 \%$ and timolol $0.5 \%$ (Taptiqom $^{\circledR}$ ) to those of the individual components. ${ }^{10}$ Patients had to be on prior prostaglandin/timolol $0.5 \%$ therapy for at least 2 weeks before screening and needed to have an IOP of $20 \mathrm{mmHg}$ (prostaglandin) or $22 \mathrm{mmHg}$ (timolol) and after run-in, washout and then study treatment for 6 months. Patients had OAG or ocular hypertension inadequately controlled on prior timolol $(n=189)$ or prostaglandin $(n=375)$ monotherapy. Included were patients with OAG or ocular hypertension inadequately controlled on prior timolol $(n=189)$ or prostaglandin $(n=375)$ monotherapy. Patients in both these groups received for 6 months either: preservative-free fixed-dose combination of tafluprost $0.0015 \%$ and timolol $0.5 \%$ (Taptiqom ${ }^{\circledR}$ ), once daily; preservative-free tafluprost $0.0015 \%$, once daily; or preservative-free timolol $0.5 . \%$, twice daily (see Figure 2). Study visits after baseline were performed at 2 and 6 weeks, 3 and 6 months and at a post-study visit. IOP was measured at 8 am, 10 am, $4 \mathrm{pm}$ and $8 \mathrm{pm}$. The mean IOP changes at month 3 showed superiority of the fixed-dose combination over tafluprost (see Figure 3A) and timolol (see Figure $3 B$ ) monotherapy; superiority was statistically significant in both strata $(p<0.05$; see Table 1). The frequency of treatment-related conjunctival hyperaemia of the fixed-dose combination was low in both strata: $4.8 \%$ and $9.5 \%$ for the prostaglandin stratum and timolol stratum, respectively, and $6.4 \%$ over the two strata. In both strata, the mean severity of conjunctival hyperaemia, evaluated by reference photographs, peaked at week 2 and then showed a downward trend during the course of the study.

\section{Non-inferiority Study of Fixed-dose Combination versus Concomitant Use of its Components}

To compare efficacy, safety and tolerability of the preservative-free fixed-dose combination and non-fixed combination of tafluprost $0.0015 \%$ and timolol $0.5 \%$, a non-inferiority study was conducted. ${ }^{1}$ This was a prospective, randomised, double-masked, activecontrolled, parallel group, multicentre phase III study including 400 patients with ocular hypertension and $O A G$, pseudo-exfoliative and pigmentary glaucoma with an IOP $\geq 23 \mathrm{mmHg}$ in at least one eye at $8 \mathrm{am}$ at baseline and $\leq 36 \mathrm{~mm}$ in both eyes at any timepoint at screening. Patients received for 6 months either: a preservativefree fixed-dose combination of tafluprost $0.0015 \% /$ timolol $0.5 \%$ $\left(\right.$ Taptiqom $\left.^{\circledR}\right)$ once daily, or preservative-free tafluprost $0.0015 \%$ once daily and preservative-free timolol $0.5 \%$ twice daily as a nonfixed combination. A comparison of mean time-wise IOP decreases, which ranged from -7.3 to $-9.1 \mathrm{mmHg}(29.6-34.6 \%)$ in the fixed-dose combination arm, and from -7.5 to $-9.4 \mathrm{mmHg}(30.7-36.0 \%)$ in the non-fixed combination arm, indicated that the fixed-dose combination therapy was equally as effective as the non-fixed combination (see

\section{Figure 2: Superiority Study - Randomisation and Treatment ${ }^{10}$}

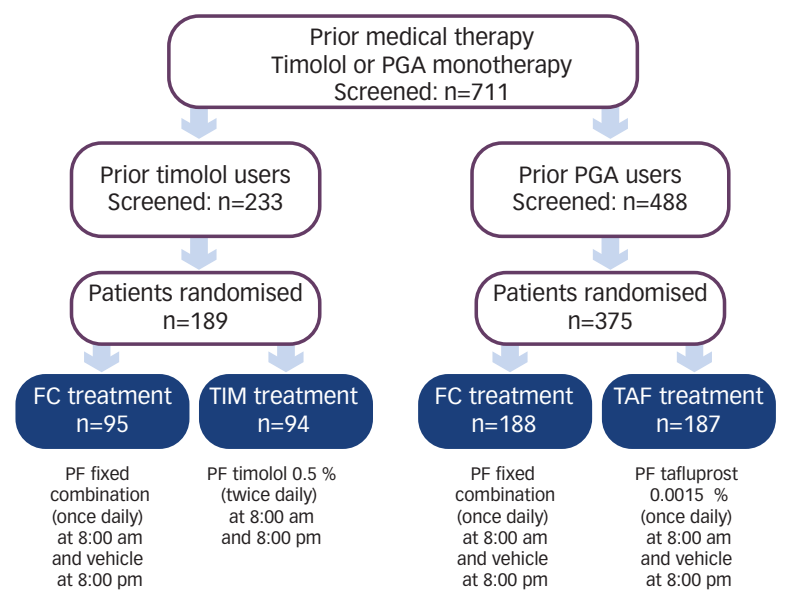

$F C=$ fixed combination: $P F=$ preservative free: $P G A=$ prostaglandin $: T A F=$ tafluprost TIM = timolol. Adapted from Pfeiffer N, Traverso CE, Lorenz K, et al., A 6-month study comparing efficacy, safety, and tolerability of the preservative-free fixed combination of tafluprost $0.0015 \%$ and timolol $0.5 \%$ versus each of its individual preservative-free components, Adv Ther, 2014;31:1228-46.

Figure 3: Fixed-dose Combination -

Superiority over Prostaglandin (A) and Timolol Monotherapy (B) ${ }^{10}$ as Shown by a Comparison of Mean IOP Change at Month $3^{10}$

A

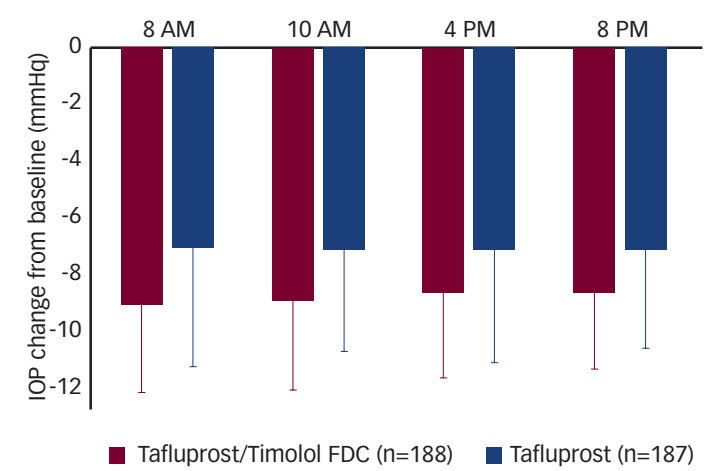

B

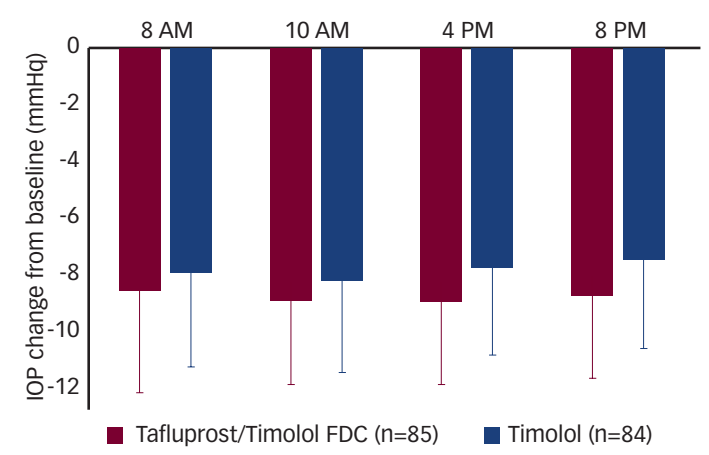

$F D C=$ fixed-dose combination; $I O P=$ intraocular pressure. Adapted from Pfeiffer $N$, Traverso CE, Lorenz K et al. A 6-month study comparing efficacy, safety, and tolerability of the preservative-free fixed combination of tafluprost $0.0015 \%$ and timolol $0.5 \%$ versus each of its individual preservative-free components, Adv Ther, 2014;31:1228-46. 


\section{Figure 4: Non-inferiority Study - Intraocular Pressure Change with Tafluprost/Timolol Fixed and Non-fixed Combination ${ }^{11}$}

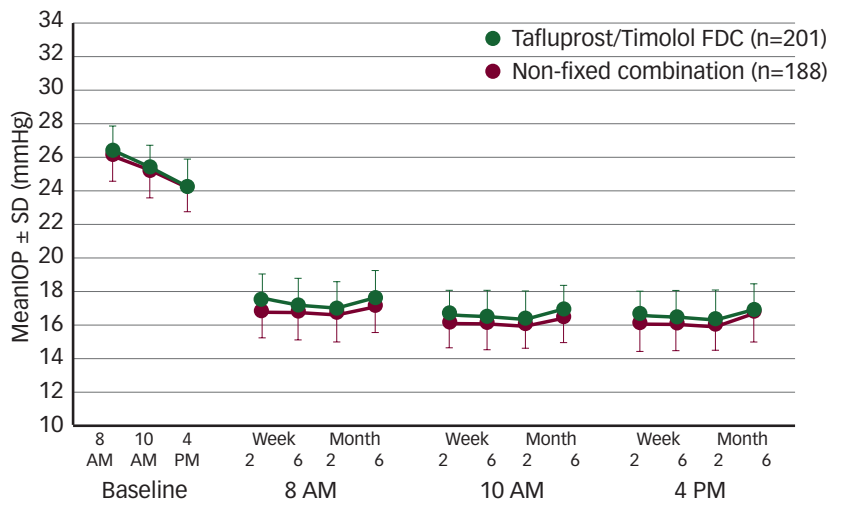

Adapted from Hollo G, Hommer A, Anton Lopez A, Ropo A, Efficacy, safety, and tolerability of preservative-free fixed combination of tafluprost $0.0015 \% /$ timolol $0.5 \%$ versus concomitant use of the ingredients, J Ocul Pharmacol Ther, 2014;30:468-75.

Figure 4). ${ }^{11}$ According to the set non-inferiority criterion of a primary efficacy endpoint, this was based on the change from baseline in the average diurnal IOP (treatment difference of the groups) at 6 months, and not on the timewise decreases, although these also proved to be non-inferior. The equivalent efficacy between the fixed-dose and non-fixed combination arms was achieved despite a lesser degree of timolol exposure in the non-fixed arm (once-daily, preservative-free, fixed-dose combination). Conjunctival/ocular hyperaemia was the most common treatment-related adverse event and was found in $8 \%$ of patients in the fixed-dose combination arm and $5 \%$ of patients in the non-fixed combination arm. The severity of hyperaemia was comparable in both treatment arms (mean change from baseline of approximately 0.2 on a $0-4$ scale). The mean change of severity score was highest at week 2 and declined thereafter.

\section{Tafluprost/Timolol Fixed-dose Combinations in Comparison with Other Prostaglandin/ Timolol Combinations}

To review the performance of preservative-free tafluprost/timolol fixeddose combination in glaucoma with that of the other prostaglandintimolol fixed-combination products on the market, 16 published double-masked, controlled phase III clinical trials with the four fixedcombination products latanoprost/timolol, bimatoprost/timolol, travoprost/timolol and tafluprost/timolol have been analysed. ${ }^{12}$ Only double-masked studies with a washout of previous IOP-lowering medication before the initiation of the treatment with the combination product were selected. The scatter plot showing the mean IOP changes at 3 months versus mean baseline IOP for the fixed prostaglandin-timolol combination products are presented in Figure 5; the mean baseline IOP appeared to predominantly determine the magnitude of the IOP reduction. The IOP reduction with tafluprost/timolol was similar to that of other prostaglandin-timolol fixed combination productions. With the tafluprost/timolol fixed-dose combination, the IOP reduction from untreated baseline was between $28-40 \%$. Further, the IOP reduction with tafluprost/timolol fixed-dose combination is similar to other fixeddose combinations based on authority-approved labelling. ${ }^{13-15}$

\section{Safety and Tolerability of the Tafluprost/ Timolol Fixed-dose Combination}

In a review summarising safety and tolerability of the preservative-free $0.0015 \%$ tafluprost $/ 0.5 \%$ timolol fixed-dose combination, the fixed

\section{Figure 5: Mean Diurnal IOP Lowering Efficacy of Prostaglandin/Timolol Fixed- dose Combinations Depending on Untreated Baseline IOP at Month $3^{12}$}

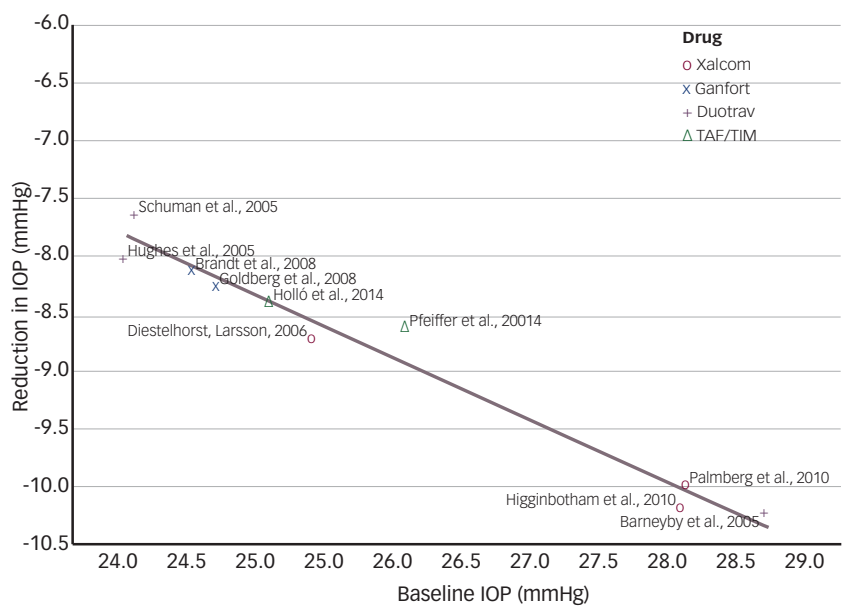

$I O P=$ intraocular pressure. Adapted from Hollo G, vuorinen J, Tuominen J, et al., Fixeddose combination of tafluprost and timolol in the treatment of open-angle glaucoma and ocular hypertension: comparison with other fixed-combination products, Adv Ther, 2014,31:932-44.

Table 1: Superiority of Tafluprost/Timolol Fixed Combination Over the Ingredients ${ }^{10}$

\begin{tabular}{llll} 
RM ANCOVA ITT & PF FC versus & PF FC versus & PF FC versus \\
Dataset (Month 3) & $\begin{array}{l}\text { Monotherapy } \\
\text { PF TIM (Primary }\end{array}$ & $\begin{array}{l}\text { PF TIM (without PF TAF } \\
\text { with Outlier) }\end{array}$ & $\begin{array}{l}\text { Outlier) } \\
\text { Monotherapy }\end{array}$ \\
\hline Difference (mmHg) & -0.885 & -1.136 & -1.516 \\
Upper 95 \% Cl & -0.024 & -0.379 & -0.988 \\
Lower 95 \% Cl & -1.745 & -1.897 & -2.044 \\
P value & 0.044 & 0.004 & $<0.001$
\end{tabular}

RM ANCOVA = a repeated-measures analysis of the covariance; $I T T=$ intent-totreat: $P F=$ preservative-free; $F C=$ fixed combination; $T I M=$ timolol; $T A F=$ tafluprost Adapted from Pfeiffer $N$, Traverso CE, Lorenz K, et al., A 6-month study comparing efficacy, safety, and tolerability of the preservative-free fixed combination of tafluprost $0.0015 \%$ and timolol $0.5 \%$ versus each of its individual preservative-free components, Adv Ther, 2014;31:1228-46.

\section{Table 2: Frequency of Conjunctival Hyperaemia and Ocular Irritation of Prostaglandin Analogue/Timolol Fixed Combinations ${ }^{16}$}

\begin{tabular}{llll} 
Prostaglandin Analogue/Timolol & $\begin{array}{l}\text { Duration of } \\
\text { Treatment } \\
\text { Fixed Combination }\end{array}$ & $\begin{array}{l}\text { Conjunctival Ocular } \\
\text { Hyperaemia } \\
\text { (Months) }\end{array}$ & $\begin{array}{l}\text { (\%) } \\
\text { Irritation }\end{array}$ \\
$\begin{array}{llll}\text { Tafluprost/timolol (preservative-free) } \\
\text { Latanoprost/timolol (preserved) }\end{array}$ & 6 & $6.4-8.0$ & $7.0-12.7$ \\
\hline Travoprost/timolol (preserved) & $3-12$ & $1.8-8.5$ & $2.3-9.0$ \\
\hline Bimatoprost/timolol (preserved) & $3-12$ & $10.8-14.3$ & $11.5-23.6$ \\
\hline Bimatoprost/timolol & 3 & 21.2 & 14.4
\end{tabular}

(preservative-free)

Adapted from: Hollo G, Katsanos A. Safety and tolerability of the tafluprost/timolol fixed combination for the treatment of glaucoma, Expert Opin Drug Saf, 2015;14:609-17.

combination demonstrated improved tolerability compared with other combinations of the prostaglandin analogue/timolol class. ${ }^{16}$ Conjunctival 
hyperaemia, which was the most common side effect, was mild in severity and occurred in only $6.4-8 \%$ of patients during 6 months of treatment (see Table 2). Figures for ocular irritation were likewise low (7.0-12.7\%). Furthermore, the fixed-dose combination of tafluprost $0.0015 \%$ and timolol $0.5 \%$ has been shown to provide a significant IOP reduction in pseudo-exfoliative glaucoma. ${ }^{17}$ Mean time-wise IOP fell by 8.62 to $10.25 \mathrm{mmHg}$ (31.8 to $36.7 \%$ ) in the fixed-dose combination arm (15 patients) and by 5.38 to $11.35 \mathrm{mmHg}(21.3$ to $41.2 \%$ ) in the non-fixed combination arm (13 patients) ( $p<0.001$ for all comparisons).

\section{Summary}

Novel preservative-free tafluprost/timolol fixed-dose combination:

- lowers IOP effectively;

- is superior to its individual components;

- is non-inferior to its individual components given concomitantly;

- provides mean diurnal IOP lowering of up to $40 \%$ from baseline at 3 months and demonstrates similar efficacy with other prostaglandin/timolol fixed-dose combinations; and

- is well-tolerated and, as a prostaglandin-containing product, is associated with a low prevalence of hyperaemia.

\title{
Structure and Function in the Diagnosis of Glaucoma
}

\author{
Lutz E Pillunat \\ University - Eye Hospital Dresden, Germany
}

Glaucoma is characterised by chronic retinal ganglion cell (RGC) damage that is not detected by automated perimetry until between 25 and $35 \%$ of the RGCs have been lost. ${ }^{18}$ Another tool would therefore be useful to identify glaucoma in patients with suspicious optic nerve morphology or high IOP. The pattern electroretinogram (PERG) directly reflects RGC function. ${ }^{19} \mathrm{~A}$ longitudinal study of 64 glaucoma suspects with ocular hypertension was performed. ${ }^{19}$ PERG, in particular the PERG ratio, detected conversion of these patients to a diagnosis of glaucoma patients 4 years before apparent visual field changes. Over the course of this study, 13 eyes converted to glaucoma (mean followup 10.3 years); PERG ratio, peak time and amplitude were significantly lower in converters. In patients who are glaucoma suspects, PERG signal appears to anticipate an equivalent loss of the optical coherence tomography signal by several years. ${ }^{20}$ The time lag between PERG amplitude and retinal nerve fibre layer (RNFL) thickness to lose $10 \%$ of their initial values is in the order of 8 years. Estimates suggested that the PERG amplitude takes 1.9 to 2.5 years to lose $10 \%$ of its initial amplitude, whereas the RNFL thickness takes 9.9 to 10.4 years to lose $10 \%$ of its initial thickness. Thus, functional damage can be detected before any structural damage occurs.

Often, more advanced optic nerve damage is observed clinically in NPG compared with HPG is observed clinically. This represents a discrepancy with the view of NPG and HPG as essentially being the same disease. Graefe pointed out in 1850 that optic disc nerve damage could be observed in the absence of any IOP elevation. To examine differences in function, the morphology has to be identical; conversely, to examine differences in morphology, the function has to be identical. Due to variations and the psychophysiological background, visual fields are often difficult to compare; therefore, optic nerve damage has to be similar (including optic disc size). With equal levels of glaucoma-based structural damage of the optic nerve head indicated by cupping, rim area and rim volume, NPG patients seem to have a less-affected visual field and a better preserved nerve fibre layer than HPG patients. ${ }^{21}$ This was a retrospective, pairmatched, comparative study that included 126 patients with NPG and 126 patients with HPG. Based on the Heidelberg Retina Tomograph, NPG and HPG patients showed comparable structural damage of the optic nerve head without a statistically significant difference between both groups (mean, NTG/HPG: disc area 2.32/2.32 mm²; $\mathrm{p}=0.342$; rim area 1.03/1.00 mm²; $\mathrm{p}=0.279$; rim volume 0.2/0.19 $\mathrm{mm}^{3} ; \mathrm{p}=0.274$ ).

Thus, the questions arise as to whether NPG patients lose predominantely connective tissue first, whether NPG and HTG really are the same disease, why do HTG patients show earlier and more pronounced visual field loss and whether this is due to the effects of IOP or an aspect of biomechanics.

\section{Summary}

- Functional damage (PERG) can be detected before any structural damage occurs.

- NPG patients show less visual field loss and less RNFL compared with same optic nerve head morphology HPG patients.

- NPG patients seem to lose connective tissue first whereas HPG patients seem to lose retinal nerve fibres first.

\section{Conclusions and Future Directions}

A preservative-free fixed-dose combination of $0.0015 \%$ tafluprost and $0.5 \%$ timolol maleate is now available for the treatment of glaucoma, which has shown in clinical trials to be effective and well tolerated with a low prevalence of hyperaemia. In addition to this improvement in the medical treatment of glaucoma, electrophysiological techniques are also improving. With methodological advances, an objective test may become available for the early diagnosis of glaucoma and allow for its prompt treatment.

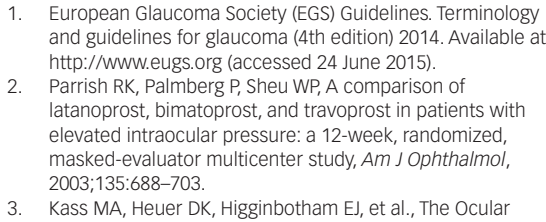

3. Kass MA, Heuer DK, Higginbotham EJ, et al., The Ocular

Hypertension Treatment Study: a randomized trial determines that topical ocular hypotensive medication delays or prevents the onset of primary open-angle glaucoma, Arch Ophthalmol 2002;120:701-13: discussion 829-30.

4. Patel SC, Spaeth $\mathrm{GL}$, Compliance in patients prescribed eyedrops for glaucoma, Ophthalmic Surg 1995:26.233-6. Chroi SS, Makoid MC Eriksen SP, Robinson IR, Drop size and initial dosing frequency problems of topically applied and initial dosing frequency problems of topically applie
ophthalmic drugs, J Pharm SCi, 1974;63:333-8.
6. Erb C, Gast U, Schremmer D, German register for glaucoma patients with dry eye. I. Basic outcome with respect to dry eye, Graefes Arch Clin Exp Ophthalmol, 2008:246:1593-601.

7. Rossi GC, Tinelli C, Pasinetti GM, et al., Dry eye syndromerelated quality of life in glaucoma patients, Eur J Ophthalmol, 2009:19:572-9.

8. Leung EW, Medeiros FA, Weinreb RN, Prevalence of ocular surface disease in glaucoma patients, I Glaucoma 2008;17:350-5. 
9. Santen Announces Positive Outcome of the European Decentralized Procedure for Approval of TAPTIQOM ${ }^{\oplus}$ [press release]. 10/22/2014 2014

10. Pfeiffer $\mathrm{N}$, Traverso CE, Lorenz K, et al., A 6-month study comparing efficacy, safety, and tolerability of the preservativefree fixed combination of tafluprost $0.0015 \%$ and timolol $0.5 \%$ versus each of its individual preservative-free components, Adv Ther, 2014:31:1228-46.

11. Hollo G, Hommer A, Anton Lopez A, Ropo A, Efficacy, safety, and tolerability of preservative-free fixed combination of and tolerabilty of preservative free fixed combination of the ingredients, Ocul Pharmacol Ther, 2014:30:468-75.

the ingredients, J Ocul Pharmacol Ther, 2014,30.468-75.

2. Hollo G, Vuorinen J, Tuominen J, et al., Fixed-dose combination of tafluprost and timolol in the treatment of open-angle glaucoma and ocular hypertension: comparison with other fixed-combination products, Adv Ther, 2014;31:932-44.

3. Summary of Product Characteristics. TAPTIQOM 15 MICROGRAMS/ML + 5 MG/ML EYE DROPS SOLUTION IN
SINGLE-DOSE CONTAINER. Available from: http://www. mhra.gov.uk/spc-pil/?prodName=TAPTIQOM \%2015 \%20 MICROGRAMS/ML \%20//// \%205 \%20MG/ML \%20EYE \%20 DROPS \%20 \%20SOLUTION \%20IN \%20SINGLE-DOSE \%20CO NTAINER\&subsName=TAFLUPROST\&pageID=SecondLevel (accessed 24 June 2015)

14. Summary of Product Characteristics. DuoTrav eye drops solution 2015. Available from: https://www.medicines.org.uk/ emc/medicine/17774 (accessed 24 June 2015).

15. European Medicines Agency. European public assessment reports GANEORT 2013. Available from: http:/wmwema. europa medicines/00 medicines/00068/human_med__ooso4.jsp\&mid=WCOb 1ac058001d125\&murl=m (accessed 24 June 2015)

16. Hollo G, Katsanos A, Safety and tolerability of the tafluprost/ timolol fixed combination for the treatment of glaucoma, Expert Opin Drug Saf, 2015;14:609-17.
17. Hollo G, Ropo A, Intraocular pressure decrease with preservative-free fixed and unfixed combination of tafluprost and timolol in pseudoexfoliative glaucoma, Curr Med Res Opin, 2015;31:13-6.

18. Kerrigan DF, Mitchell RS, Number of ganglion cells in glaucoma eyes compared with threshold visual field tests in the same persons, Invest Ophthalmol Vis Sci, 2000:41:741-8.

19. Bode SF, Jehle T, Bach M, Pattern electroretinogram in glaucoma suspects: new findings from a longitudinal study, Invest Ophthalmol Vis Sci, 2011:52:4300-6.

20. Banitt MR, Ventura LM, Feuer WJ, et al. Progressive loss of retinal ganglion cell function precedes structural loss by several years in glaucoma suspects, Invest Ophthalmol Vis SCi, 2013;54:2346-52.

21. Hantzschel J, Terai N, Sorgenfrei F, et al.,Morphological and functional differences between normal-tension and hightension glaucoma, Acta Ophthal, 2013;91:e386-91.
Product name: TAPTIQOM ${ }^{\circledR} 15$ micrograms $/ \mathrm{ml}+5 \mathrm{mg} /$ $\mathrm{ml}$ eye drops, solution in single-dose container Composition: One drop (about $30 \mu$ l) contains about 0.45 micrograms of tafluprost and $0.15 \mathrm{mg}$ of timolol. One single-dose container $(0.3 \mathrm{ml})$ of eye drops contains 4.5 micrograms of tafluprost and $1.5 \mathrm{mg}$ of timolol. Please refer to the Summary of Product Characteristics (SMPC) for a full list of excipients. Indication: Reduction of intraocular pressure in adult patients with open angle glaucoma or ocular hypertension who are insufficiently responsive to topical monotherapy with beta-blockers or prostaglandin analogues and require a combination therapy, and who would benefit from preservative free eye drops.

Posology and method of administration: Recommended dose is one drop in the conjunctival sac of the affected eye(s) once daily. Not to exceed one drop per day in the affected eye. Not recommended in children or adolescents (under the age of 18). In renal or hepatic impairment use with caution. To reduce systemic absorption, patients should be advised to use nasolacrimal occlusion or close the eyelids for 2 minutes after instillation. Excess solution should be wiped away to reduce the risk of darkening of eyelid skin. If more than one ophthalmic product is used, five minutes should separate their administration. Contact lenses should be removed before instillation.

Contraindications: Hypersensitivity to the active substances or to any of the excipients. Reactive airway disease including bronchial asthma, or a history of bronchial asthma, severe chronic obstructive pulmonary disease. Sinus bradycardia, sick sinus syndrome, including sino-atrial block, second or third degree atrioventricular block not controlled with pacemaker. Overt cardiac failure, cardiogenic shock. Warnings and precautions: Before initiating treatment, patients should be informed of the possibility of eyelas growth, darkening of the eyelid skin and increased iris pigmentation related to tafluprost. These changes may be permanent, and lead to differences in appearance between the eyes if only one eye is treated. Similar cardiovascular, pulmonary and other adverse reactions as seen with systemic beta-adrenergic blocking agents may occur. The incidence of systemic adverse reactions after topical ophthalmic administration is lower than with systemic administration. Caution should be exercised when prescribing TAPTIQOM ${ }^{\circledast}$ to patients with cardiac or severe peripheral vascular disorders eg Raynaud's disease or syndrome. Use with caution in patients with mild/moderate COPD and in patients subject to spontaneous hypoglycaemia or labile diabetes. Beta-blockers may mask signs of hyperthyroidism and block systemic beta-agonist effects such as those of adrenaline. Anaesthetists should be informed when a patient is receiving timolol. Patients with a history of severe anaphylactic reaction may be more reactive to repeated challenge with such allergens and be unresponsive to the usual doses of adrenaline used to treat anaphylactic reactions. The known effects of systemic beta blockers may be potentiated when TAPTIQOM ${ }^{\circledR}$ is given concomitantly. The use of two topical beta-blockers is not recommended. Patients with corneal disease should be treated with caution as ophthalmic beta-blockers may induce dry eyes. When timolol is used to reduce elevated intraocular pressure in angle-closure glaucoma, always use a miotic. Caution is recommended when using tafluprost in aphakic patients, pseudophakic patients with torn posterior lens capsule or anterior chamber lenses, and in patients with known risk factors for cystoid macular oedema or iritis/uveitis. Please see the SMPC for further information.

\section{Interactions with other medicinal products:}

Potential for hypotension/marked bradycardia when administered with oral calcium channel blockers, beta-adrenergic blockers, anti-arrhythmics, digitalis glycosides, parasympathomimetics and guanethedine. Please refer to the SMPC

Pregnancy: Do not use in women of childbearing age/ potential unless adequate contraceptive measures are in place.

Breast-feeding: It is not recommended to breast-feed if treatment with TAPTIQOM ${ }^{\circledast}$ is required. Driving and using machines: If transient blurred vision occurs on instillation, the patient should not drive or use machines until clear vision returns. Undesirable effects: Conjunctival/ocular hyperaemia occurred in approximately $7 \%$ of patients participating in clinical studies with TAPTIQOM ${ }^{\oplus}$. Other common side effects include: eye pruritus, eye pain, change of eyelashes (increased length, thickness and number of lashes), eyelash discolouration, eve irritation, foreign body sensation, blurred vision, photophobia. Adverse reactions that have been seen with either of the active substances (tafluprost or timolol) and may potentially occur also with TAPTIQOM ${ }^{\circledR}$ include: increased iris pigmentation, anterior chamber cells/flare, iritis/ uveitis, deepening of eyelid sulcus, hypertrichosis of eyelid, exacerbation of asthma, dyspnea, allergy, angioedema, urticaria, anaphylaxis, hypoglycaemia, syncope, ptosis, bradycardia, chest pain, palpitations, oedema, cardiac arrest, heart block, AV block, cardiac failure. Please also see the SMPC.

Overdose: Treatment should be symptomatic and supportive.

Special precautions for storage: Store in a refrigerator $\left(2-8^{\circ} \mathrm{C}\right)$. After opening the foil pouch keep the single-dose containers in the original pouch and do not store above $25^{\circ} \mathrm{C}$. Discard open single-dose containers with any remaining solution immediately after use.

Package quantities and basic NHS cost: $30 \times 0.3 \mathrm{ml}$ single-dose containers $£ 14.50$

Product licence holder: Santen Oy, Niittyhaankatu 20 , 33720 Tampere, Finland (PL 16058/0012). Price: $30 \times 0.3 \mathrm{ml}$ single-dose containers $£ 14.50$ Date of authorisation: 30/10/2014 POM. Date of prescribing information: 31/05/2015.

Adverse events should be reported. Reporting forms and information can be found at www.mhra.gov.uk/ yellowcard. Adverse events should also be reported to Santen UK Limited (Email medinfo@santen.uk or telephone: 0845075 4863)

Date of preparation: December 2015 Job code: STN 11117 TAP 00027 (eu). EU code GLA-001-15 